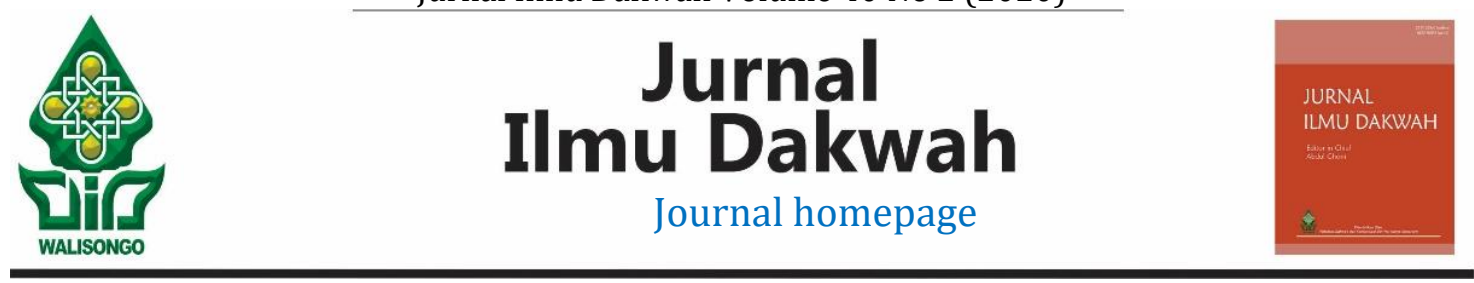

\title{
Eksistensi komunitas hijrah dan dakwah masa kini: Studi komunitas jaga sesama Solo
}

\author{
Abraham Zakky Zulhazmi ${ }^{1}$ \& Erma Priyanti ${ }^{2}$ \\ 1IAIN Surakarta \\ Email: abrahamzakky@gmail.com \\ 2IAIN Surakarta \\ Email: erma.rianty28@gmail.com
}

\begin{abstract}
In this paper the development of da'wa in contemporary Indonesia is marked by the phenomenon of the spread of hijrah communities in various cities. Hijrah has become a familiar phenomenon among the Muslim community. For Muslims, hijrah has become a predictable phenomenon. In this case, it is explained that hijrah is a way to change an individual or repent. Whether done by each individual or community. One of them is Solo, which has a dynamic diversity and religious background. This research is qualitative research that describes the da'wa management in Komunitas Jaga Sesama Solo. Interviews with Komunitas Jaga Sesama Solo managers (head of public relations and members) were used as the primary data collection method. This study concluedes that the Komunitas Jaga Sesama Solo carries out da'wa management to accommodate the young generation of Solo to learn the basics of Islam. Da'wa planning (takhthith) is pursued through determining the target of the da'wa, compiling the vision and mission of the community, choosing the ustaz. Organizing da'wa (tanzhim) by distributing tasks to community administrators. The movement of da'wa (tawjih) by presenting activities that are relevant to the younger generation and optimization of social media. Control and evaluation of da'wa (riqabah) by monthly evaluation.
\end{abstract}

Keyword: Hijrah Community; Da'wa; Jaga Sesama.

\begin{abstract}
Abstrak
Tulisan ini menunjukkan perkembangan dakwah kontemporer di Indonesia ditandai dengan fenomena maraknya komunitas hijrah diberbagai Kota. Bahkan, hijrah sudah menjadi sebuah fenomena yang tak asing dan bahkan familiar di kalangan masyarakat Islam. Bagi pemeluk agama Islam, hijrah sudah menjadi fenomena yang ramai dilakukan. Dalam hal ini dijelaskan bahwa hijrah sebagai jalan untuk mengubah seorang individu atau bertaubat. Baik yang dilakukan oleh setiap individu ataupun dalam sebuah komunitas. Salah satunya di Kota Solo yang memiliki latar keberagamaan dan keberagaman yang dinamis. Tujuan penelitian ini untuk menguraikan secara detail tentang pengelolaan dakwah dalam komunitas Jaga Sesama Solo. Penelitian ini merupakan jenis penelitian kualitatif yang menjelaskan mengenai manajemen dakwah di Komunitas Jaga Sesama Solo. Metode pengumpulan data yang digunakan yaitu wawancara, observasi
\end{abstract}


dan dokumentasi. Adapun wawancara mendalam (indept interview) dengan pengelola komunitas Jaga Sesama (ketua, bagian humas dan anggota). Hasil penelitian ini adalah Komunitas Jaga Sesama menjalankan dalam menajemen dakwah untuk mewadahi generasi muda Solo belajar dasar Islam. Perencanaan dakwah (takhthith) ditempuh melalui menentukan sasaran dakwah, menyusun visi misi komunitas, memilih ustaz. Pengorganisasian dakwah (tanzhim) dengan pembagian tugas kepada pengurus komunitas. Penggerakan dakwah (tawjih) dengan menghadirkan kegiatan yang relevan dengan generasi muda dan optimalisasi media sosial. Pengendalian dan evaluasi dakwah (riqabah) melalui evaluasi bulanan.

Kata kunci: Komunitas Hijrah; Dakwah; Jaga Sesama.

\section{PENDAHULUAN}

Hijrah dalam perkembangan beberapa tahun terakhir ini menjadi sebuah istilah yang mengemuka di ruang publik. Hijrah yang dimaksud di sini bukan bermakna berpindahnya Nabi Muhammad SAW dari Makkah ke Madinah. Namun, hijrah dalam hal ini lebih dekat dengan istilah taubat atau berubahnya individu menjadi "pribadi yang lebih baik". Di Indonesia istilah hijrah mulai mulai muncul di tahun 2000 (Sunesti, dkk, 2018). Ditandai misalnya dengan sejumlah musisi yang memilih meninggalkan band dan memilih jalan hidup yang lebih "islami". Saat itu hijrah masih berupa aktivitas personal, belum dikomodifikasi dan terlembagakan. Beda dengan saat ini ketika komunitas-komunitas hijrah menjamur seiring makin menguatnya dakwah di media sosial (Zulhazmi dan Hastuti, 2018).

Mereka yang "berhijrah" lazimnya mengubah penampilan. Perempuan yang sebelumnya tidak berjilbab memutuskan mengenakan jilbab lebar atau yang populer dengan sebutan jilbab syar'i. Sedangkan para lelaki mengubah penampilan dengan jenggot dan celana di atas mata kaki sebagai penanda (Sunesti, dkk, 2018). Fenomena serupa itu dapat kita lihat pada sejumlah selebritas yang memilih untuk hijrah dan membuat pernyataan di ruang publik. Beberapa bahkan secara tegas meninggalkan pekerjaan lama mereka yang dianggap sebagai dosa dan maksiat.

Munirul Ikhwan menyebut "propaganda hijrah" memiliki posisi penting dalam wacana Islamisme. Menurutnya, sebagian generasi muda Muslim hari ini ingin "berhijrah" karena adanya anggapan bahwa menjadi Muslim saja tidak cukup. Mereka harus "berhijrah", menjadi muslim yang taat dan "utuh" (Ikhwan, 2018). Konsep muslim yang "utuh" ini dekat dengan istilah ber-Islam secara kaffah. Maksud dari kaffah adalah menyeluruh, artinya ber-Islam tidak hanya dari satu sisi, tapi secara komprehensif. Menerapkan ajaran Islam tidak hanya pada diri sendiri tetapi juga masyarakat dan negara (Ahmadiy, 2016). Ber-Islam secara kaffah oleh peneliti lain juga dimaknai sebagai upaya memandang Islam secara integratif, tidak tepisah-pisah. Bahwa Islam bisa hadir di semua "lapangan", baik ekonomi, politik, sains, budaya, dan lain-lain, tidak sekadar aspek ritual belaka (Ritonga, 2016).

Perkembangan berikutnya menunjukkan fenomena hijrah di Indonesia semakin terorganisir. Kita melihat maraknya komunitas-komunitas yang menyebut diri sebagai komunitas hijrah. Sebut saja misalnya komunitas Shift, Yuk Ngaji dan Fast. Ketiga komunitas tersebut memiliki tokoh sentral, Shift menjadikan Hanan Attaki sebagai seorang tokoh yang berpengaruh di dalamnya. Komunitas hijrah yang berbasis di Bandung itu fokus berdakwah kepada generasi muda. Sedangkan Komunitas Yuk Ngaji didirikan 
sejumlah tokoh salah satunya adalah Felix Siauw, seorang mualaf yang pernah bergabung dengan Hizbut Tahrir Indonesia.

Felix Siauw disebut sebagai produsen wacana islamis, yang membangun legitimasi dari penglaman hijrah (Ikhwan, 2018). Sedangkan hijrah sendiri adalah konsep Islamis yang menerangkan kenapa wacana Islamisme populer di masyarakat perkotaan. Kisah perjalanan Felix Siauw menjadi mualaf menjadi salah satu kisah hijrah yang digemari sejumlah orang (utamanya anak muda), yang meneguhkan posisi Felix Siauw sebagai "ustaz hijrah". Selain melalui media sosial, Felix Siauw mengemas gagasannya dalam sejumlah judul buku yang tergolong buku laris. Fakta tersebut mengingatkan kita pada riset yang mengupas secara mendalam dakwah Felix Siauw (Hew, 2018).

Terdapat sejumlah penelitian yang membahas fenomena komunitas hijrah. Di antaranya adalah penelitian Hadri Hasan yang menjelaskan bahwa gerakan hijrah sudah menjadi tren di kalangan muslim, khususnya remaja di Ibu Kota. Jutaan remaja yang hadir di Hijrah Festival menunjukkan pencarian jati diri mereka menuju "shirotol mustaqim" melalui hijrah. Gerakan ini menjadi populer karena dipengaruhi juga oleh banyaknya artis Ibu Kota yang menjadi influencer gerakan hijrah. Remaja mempunyai role model dalam gerakan hijrahnya (Hadri, 2019).

Bertema serupa, riset Kirana Nur Lyansari menunjukkan bahwa motif hijrah para selebriti, selain karena faktor ideologi keislaman yang dianut, juga ada faktor ekonomi di belakangnya. Mereka membranding dirinya sendiri melalui tampilan dan gaya hidup berpakaian yang islami. Berdasarkan ketiga artis yang menjadi objek penelitian (Riris Setyo Rini, Sakti eks Sheila on 7, Febrianti Almeera), semuanya mempunyai lini komoditas ekonomi di mana mereka adalah pendirinya. Sebagai public figure, ini memudahkan mereka untuk memasarkan produk yang mereka jual. Bagaimanapun juga, artis mempunyai tempat tersendiri di hati fansnya (Lyansari, 2018).

Adapun penelitian Matan Uberman dan Shaul Shay melihat hijrah yang dimaknai sekarang sudah bergeser dari makna aslinya. Jika dulu adalah hijrahnya Nabi Muhammad dari Mekah ke Madinah, sekarang lebih dimaknai sebagai gerakan teror yang digawangi oleh IS untuk menaklukkan wilayah jajahannya. Mereka (IS) berhasil memanipulasi makna konsep hijrah untuk memuluskan agenda militer dan kepentingan politik praktis. Salah satu penyebaran mazhab mereka melalui majalah Dabiq yang mereka buat sendiri dalam rangka berdirinya negara Islam (Uberman dan Shay, 2016).

Berikutnya, riset berjudul Hijrah Milenial: Antara Kesalehan dan Populism yang secara kritis menyoroti dangkalnya fenomena hijrah yang ditampilkan di media sosial (hanya sebatas soal pakaian, pernikahan, dan semacamnya). Sehingga, kesan yang muncul justru hijrah artifisial dan simbolik (Annisa, 2018). Senada dengan penelitian tersebut, Amna melihat hijrah yang dilakukan para artis belakangan ini sebagai suatu bentuk komodifikasi. Ia melihat agama sebagai sesuatu yang diperjualbelikan (Amna, 2019). Namun tidak hanya itu, hijrah para artis juga dianggap hanya sebagai gimmick dan sarana membuat sensasi.

Sementara itu, Fajriani dan Sugandi memandang hijrah sebagai penguat identitas keislaman pada kalangan muslim milenial (Fajriani dan Sugandi, 2019). Keduanya menandai peran media sosial dan banyaknya public figure atau artis yang menyatakan diri berhijrah sebagai penyebab menguatnya fenomena hijrah beberapa tahun terakhir. Hijrah sebagai identitas diri juga menguatkan riset Prasanti dan Indriani yang meneliti 
kontrsuksi makna hijrah komunitas Lets Hijrah pada media sosial Line. Anggota komunitas tersebut tidak hanya melihat hijrah sebagai perubahan diri ke arah yang lebih baik namun juga ada kaitannya dengan identitas diri (Prasanti dan Indriani, 2019).

Berkaitan dengan hijrah, media sosial dan posisi public figure, Surahman menyoroti adanya virtual public figure yang turut memengaruhi perkembangan gerakan hijrah, utamanya melalui media sosial. Surahman mengambil contoh Salman Al Jugjawy (eks anggota band Sheila on Seven) sebagai salah satu virtual public figure yang memiliki pengaruh di media sosial (Surahman, 2018). Riset tersebut serumpun dengan riset Sari, Husein, and Noviani (2020) yang mendedah strategi dakwah gerakan \#IndonesiaTanpaPacaran di media sosial. Serumpun pula dengan riset Sakhinah dan Arbi (2019) yang melihat komunikasi persuasif komunitas Terang Jakarta dalam mengajak hijrah kawula muda melalui media baru. Tak jauh berbeda, Dilawati et al. (2020) meneliti komunitas Shift Bandung, namun dengan pendekatan emik-etik.

Pada artikel berjudul Identitas Keagamaan: Pemuda Hijrah di Kalangan Anak Muda disebutkan bahwa menguatnya fenomena hijrah hari ini adalah bentuk pergeseran otoritas keagamaan yang disebabkan media baru (Wulandari, 2019). Sebagaimana kita saksikan, saat ini bermunculan "ustaz-ustaz baru" yang lahir dan besar di media baru (media sosial). Wulandari mengambil contoh Evie Effendi dan Handy Bonny yang memposisikan diri sebagai ustaz hijrah kekinian dengan ciri mengenakan atribut khas anak muda dan penggunaan bahasa gaul. Adapun menurut Dony Arung Triantoro, Eko Saputra, dan Tri Wahyuni, mengelola komunitas hijrah atau komunitas dakwah anak muda sama dengan mengelola hibriditas identitas anak muda. Mereka mencermati komunitas Teras Dakwah di Yogyakarta yang memadukan dakwah Islam dengan budaya populer (Triantoro, dkk, 2019).

Irmansyah mempertanyakan apakah pelaku hijrah yang mengubah penampilan adalah wujud dari kesalehan atau sekadar mengikuti gaya hidup (Irmansyah, 2020). Risetnya di komunitas Yuk Ngaji Yogyakarta menemukan bahwa anggota komunitas ingin mengikuti perkembangan zaman namun tetap syar'i dan saleh. Sementara itu, Farhan menemukan anggota Komunitas Biker Muslim Bengkulu memaknai hijrah sebagai perubahan dari perbuatan yang menjauh dari Allah menuju perbuatan yang mendekatakan diri pada Allah (Farhan, 2020). Adapun praktik hijrah di komunitas itu berkisar pada tiga hal, yakni salat, sedekah/zakat dan menjalin persaudaraan.

Riset lain tentang hijrah dilakukan A. N. Sari and Mahadian (2018). Keduanya melihat motif dan perilaku komunikasi orang-orang yang memutuskan untuk berhijrah. Ditemukan setidaknya tiga dorongan dalam keputusan berhijrah, yakni dorongan masa lalu, dorongan teman dan dorongan masa depan. Di sisi lain, sorotan kritis terhadap gerakan hijrah disampaikan Addini (2019), yang mengharapkan gerakan hijrah menjadi gerakan substantif dan bukan simbolis. Hijrah, karena maknanya baik, seharusnya juga melahirkan anak-anak muda yang bepikiran inklusif dan toleran, bukan sebaliknya.

Mencermati riset-riset tentang hijrah di atas, kiranya belum ditemukan riset tentang manajemen dakwah suatu komunitas hijrah. Berbicara mengenai komunitas hijrah, pada konteks Kota Solo, didapati sejumlah komunitas hijrah. Kita mencatat Exspreso (Eks Preman Solo), Perisai Dakwah Solo (Pemuda Rindu Syariah), Yuk Ngaji Solo, Ngaji Asik.id, Sedulur Hijrah, dan Jaga Sesama Solo. Komunitas hijrah umumnya mengemas kajiankajian rutin mereka dengan kemasan populer. Mereka menghadirkan pendakwah- 
pendakwah muda, memilih tema-tema kekinian yang ringan serta membuat pamflet ajakan mengikuti kajian dengan desain yang atraktif dan khas anak muda. Mereka juga gencar memproduksi konten dakwah di media sosial.

Selain itu, gaya pengajian konvensional mulai ditinggalkan komunitas hijrah. Sehingga tidak mengherankan jika anak-anak muda datang ke kajian komunitas hijrah dengan celana levis dan kaus, meninggalkan sarung, peci dan baju koko yang lazim dikenakan ketika menghadiri pengajian. Beberapa komunitas hijrah juga menjual merchendise berupa kaus dan pernak pernik lain. Pola semacam itu dapat dibaca sebagai komodifikasi hijrah selain juga sebagai bentuk penguatan identitas kelompok dan upaya mendekati kalangan muda.

Adapun salah satu penanda dinamika komunitas hijrah di Kota Solo adalah digelarnya Solo Hijrah Day. Acara tersebut diinisiasi komunitas Yuk Ngaji Solo bekerjasama dengan beberapa komunitas lain. Panitia mengklaim acara tersebut mampu menyedot dua ribu orang. Sejumlah "ustaz hijrah" didatangkan, seperti Ridwanullah, Hawaariyyun, Husain Assadi, Fuadh Naim, Shifrun dan lainnya (Reno, 2019). Nama-nama ustaz itu cukup populer di lingkar komunitas hijrah. Solo Hijrah Day dapat dibaca sebagai konsolidasi komunitas hijrah di Surakarta. Pada beberapa sisi, terdapat kemiripan pola antara Solo Hijrah Day dan Hijrah Fest ("pesta" komunitas hijrah di tingkat nasional).

Komunitas Jaga Sesama Solo menarik diteliti mengingat kondisi keberagamaan di kota tersebut. Sebagaimana diketahui, Solo memiliki masyarakat yang beragam. Kelompok nasionalis tumbuh subur di Solo terlihat dari mapannya posisi PDIP di Solo. Di sana juga terdapat sejumlah pesantren, di antaranya PP Al-Muayad dengan corak NU, terdapat pula PP Al-Mukmin Ngruki dengan Abu Bakar Baasyir sebagai tokoh sentral. Solo juga menjadi kota kelahiran ormas MTA yang terus bertumbuh. Menariknya lagi, Solo memiliki Walikota seorang non muslim. Selain itu, Solo juga merupakan pusat kebudayaan Jawa, sama dengan Yogyakarta.

Gambaran di atas menunjukkan betapa kompleksnya Solo sebagai sebuah Kota. Di tengah kondisi tersebut, sebuah komunitas hijrah berkembang dan semakin mendapat pengaruh, utamanya di kalangan anak muda perkotaan. Komunitas Jaga Sesama bukan berlatar organiasi massa Islam yang mapan di Surakarta, seperti NU, Muhammadiyah, atau MTA. Sehingga menjadi hal yang menarik dipertanyakan bagaimana mereka mengembangkan dakwahnya.

Riset ini memanfaatkan teori manajemen dakwah untuk mengungkap pengelolaan dakwah komunitas Jaga Sesama Solo. Manajemen dakwah dimaknai sebagai pengaturan secara sistematis dan koordinatif dalam kegiatan atau aktivitas dakwah yang dimulai dari sebelum pelaksanaan sampai akhir dari kegiatan dakwah (Munir, 2015). Lebih rinci, manajemen dakwah meliputi perencanaan dakwah (takhthith), pengorganisasian dakwah (tanzhim), penggerakan dakwah (tawjih), dan pengendalian dan evaluasi dakwah (riqabah).

Apabila kita telusuri, terdapat riset-riset terdahulu yang membahas manajemen dakwah di sejumlah lembaga. Di antara riset tersebut adalah riset Novi Maria Ulfah yang menyoroti manajemen dakwah LDII Semarang (Ulfah, 2017). Terdapat pula riset yang mengupas praktik manajemen dakwah di Pemerintah Kota Solok Sumatra Barat (Putri, 2019) dan Sekolah Luar Biasa Islam (SLBI) Qothrunnada Yogyakarta (Hayati, 2018). Dua riset tersebut menunjukkan bahwa praktik dakwah dapat terjadi di manapun dan 
membutuhkan pengelolaan yang baik. Adapun secara, teoretik, riset Nur Alhidayatilah mengatakan bahwa manajemen dakwah di era modern yang disruptif harus dinamis dan adaptif, mengingat perubahan-perubahan terjadi begitu cepat dan tak terduga.

Penjabaran tersebut meneguhkan bahwa manajemen dakwah menjadi salah satu hal penting demi tercapainya tujuan dakwah. Lebih-lebih jika dikaitkan dengan fokus riset ini, Komunitas Jaga Sesama Solo memiliki anggota yang beragam latar belakang dan mereka baru belajar dasar-dasar Islam. Tanpa manajemen yang baik, visi misi komunitas tentu akan sukar dicapai, apalagi Komunitas Jaga Sesama Solo beranggotakan kawula muda dengan karakternya yang khas. Uraian di atas kiranya dapat menujukkan urgensi dari penilitian ini.

\section{METODE PENELITIAN}

Penelitian ini menggunakan jenis penelitian kualitatif deskriptif. Teknik pengumpulan data menggunakan studi pustaka, dokumentasi dan wawancara. Adapun informan penelitian ini adalah ketua, bagian humas dan anggota Komunitas Jaga Sesama Solo. Mereka dipilih menjadi informan karena dapat memberikan data yang dibutuhkan peneliti untuk riset ini. Selain wawancara langsung, peneliti juga turut serta dalam sejumlah kajian yang diadakan oleh Komunitas Jaga Sesama Solo di Masjid Ar-Rohman Jalan Parkit Raya Nomor 3, Manahan, Banjarsari, Surakarta. Peneliti juga mengamati unggahan-unggahan di kanal media sosial Komunitas Jaga Sesama Solo. Data-data yang diperoleh kemudian dianalisis dengan teori manajemen dakwah untuk mendapatkan gambaran mengenai manajemen dakwah yang dijalankan oleh Komunitas Jaga Sesama Solo.

\section{HASIL DAN PEMBAHASAN}

Riset-riset mengenai praktik dakwah kontemporer telah menunjukkan betapa dinamis perkembangan dakwah masa kini. Pilihan media dakwah yang beragam menjadikan dakwah tidak sebatas "khutbah di atas mimbar" belaka namun juga dakwah melalui Instagram, Youtube, podcast dan kanal-kanal lain. Organisasi atau komunitas dakwah di kalangan kelas menengah muslim perlahan juga menemukan bentuk-bentuk baru, keberadaan komunitas hijrah contohnya. Komunitas hijrah yang penting dan menarik mendapat sorotan salah satunya adalah Komunitas Jaga Sesama Solo.

Komunitas Jaga Sesama Solo didirikan pada 27 Januari 2016. Pendirian komunitas dilandasi kegelisahan sejumlah pemuda di Solo yang ingin belajar mengaji namun bingung mencari guru. Kemudian, sekelompok anak muda mencoba menjawab kebingungan itu dengan cara mengumpulkan teman-teman yang sudah bisa membaca Al Qur'an dalam suatu wadah dan kesempatan untuk berbagi ilmu. Komunitas tersebut biasa berkegiatan di Masjid Ar-Rochman, Manahan, Surakarta. Dinamakan Jaga Sesama karena pertama kali melakukan pengajian pada hari Selasa malam (Sesama). Kata "Jaga" berarti saling menjaga atau melindungi dari apapun. Kata "Sesama" bermakna sesama muslim, sesama bangsa Indonesia dan terutama sesama pemuda Solo. Komunitas Jaga Sesama Solo ingin menjaga pemuda kota Solo agar tidak terjerumus pada pergaulan yang salah (Ilham, 2018).

Terdapat tiga orang yang menjadi founder (pendiri) Komunitas Jaga Sesama Solo yakni Akso Gilang, David Pratondo, dan Dimas Rahmad D. Sedangkan Widyantoro S 
menjabat sebagai amir (ketua). Dalam mengelola komunitas mereka dibantu sekretaris dan bendahara serta sejumlah orang yang berada di divisi humas, divisi acara, divisi media dan desain. Mengingat urgensi media sosial dalam gerak komunitas hijrah, divisi media dan desain menempati posisi penting. Divisi tersebut bertugas mengelola akun-akun media sosial komunitas Jaga Sesama, mengunggah jadwal kegiatan serta foto dan video kegiatan komunitas. Sebagai sebuah komunitas, Jaga Sesama Solo memiliki sejumlah kegiatan rutin. Kegiatan komunitas Jaga Sesama Solo dapat dilihat pada tabel berikut:

Tabel 1. Daftar Kegiatan Komunitas Jaga Sesama Solo

\begin{tabular}{|c|c|}
\hline Hari & Kegiatan \\
\hline Senin & Berlatih hadroh (Hadroh Al-Asyiqin) \\
\hline Selasa & $\begin{array}{l}\text { Pagi: Dahar Gratis (kolaborasi antara komunitas Dahar } \\
\text { Gratis dan Jaga Sesama). } \\
\text { Malam: mengaji iqro, Al Qur'an, ta'lim yang dilakukan } \\
\text { secara bergilir di rumah-rumah jamaah atau masjid- } \\
\text { masjid. }\end{array}$ \\
\hline Rabu & Kajian Fiqh, dibimbing Habib Ali Bin Ali Assegaf. \\
\hline Kamis & Futsal (malam) \\
\hline Jumat & $\begin{array}{l}\text { Mengaji iqro dan Al Qur'an di masjid Ar-Rochman, } \\
\text { Manahan, Solo. }\end{array}$ \\
\hline Sabtu & Olahraga memanah atau berenang \\
\hline Minggu & Sunmori (Sunday Morning Ride) \\
\hline
\end{tabular}

Selain kegiatan rutin di atas, terdapat pula kegiatan komunitas yang dilakukan satu bulan sekali. Kegiatan tersebut di antaranya Mbois (Mbahas Obrolan islami), berupa kajian yang diisi oleh ustaz yang direkomendasikan para anggota Jaga Sesama. Kajian ini diisi materi-materi yang ringan dan mudah diterima oleh para jama'ah (anak muda yang ingin hijrah), salah satu di antaranya adalah kajian fiqih. Fiqih dasar (taharah, salat, puasa, nikah dan lainnya) dirasa perlu diajarkan kepada mereka yang benar-benar awam atau baru mulai belajar agama. Beberapa ustaz yang pernah mengisi Mbois di antaranya yaitu Ustaz Kelik Gunawan Pribadi, Ustaz Hadi Wasono, Ustaz Saddam Husein, Habib Habibi Mulachela, Habib Muhammad bin Yahya Baraqbah, Ustaz A.M. Mustain Nashoha dan lainlain.

Selain itu juga ada agenda bulanan ziarah makam ulama sekitar Solo Raya. Komunitas Jaga Sesama Solo juga memiliki kegiatan enam bulan sekali, yakni makrab (malam keakraban) yang dikemas dalam kegiatan camping atau menginap di villa, diisi games, sharing, dan mengaji bersama. Ada pula kegiatan tahunan yakni Milad Komunitas Jaga Sesama. Gus Miftah, Habib Syech dan ustaz-ustaz populer lain pernah dihadirkan dalam Milad Komunitas Jaga Sesama. 


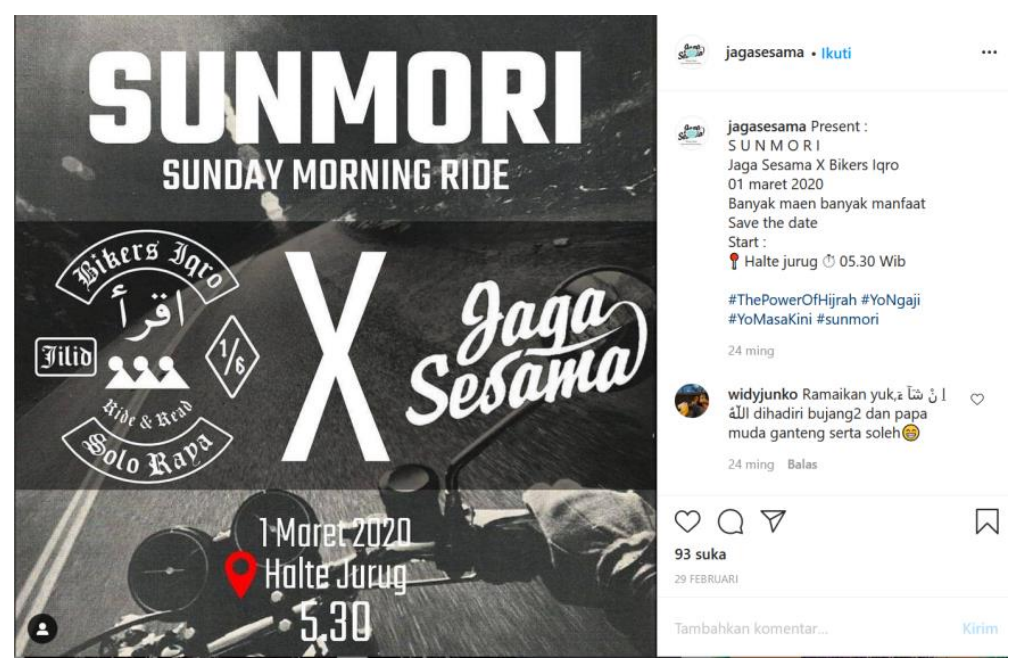

Gambar 1. Contoh Kegiatan Komunitas Jaga Sesama Solo

(Sumber: Instagram jagasesama)
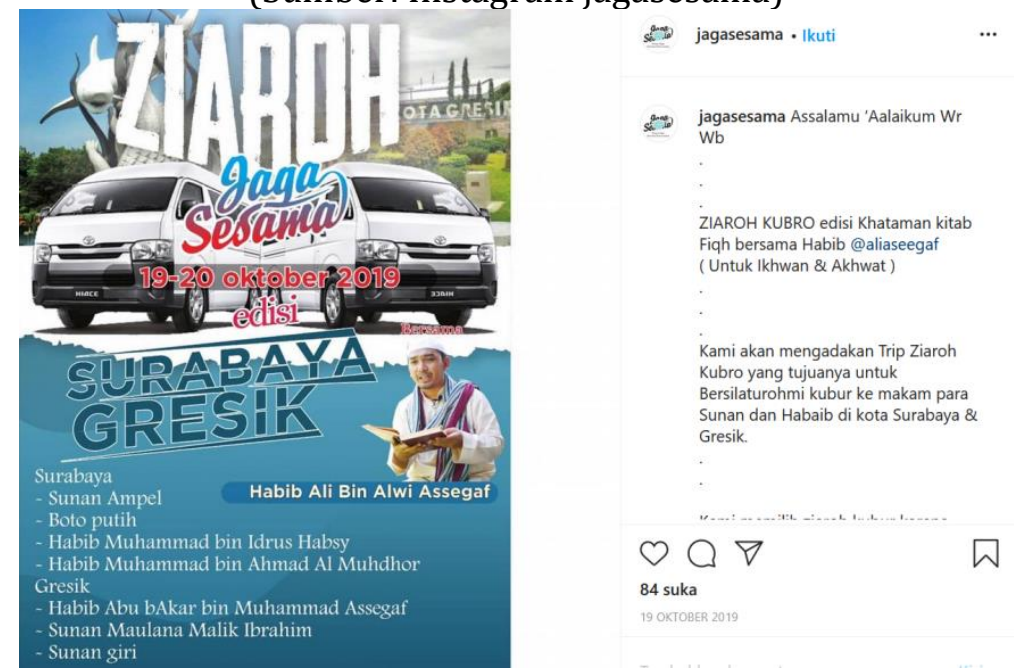

Gambar 2. Contoh Kegiatan Komunitas Jaga Sesama Solo

(Sumber: Instagram jagasesama)

Menurut pengelola Komunitas Jaga Sesama, pada mulanya anggota komunitas berjumlah 8 orang. Adapun saat ini anggota yang aktif sebanyak 30-40 orang, sementara anggota yang bergabung di grup Whatsapp Jaga Sesama berjumlah 185 orang. Pendanaan komunitas berasal dari infaq anggota, hanya untuk acara besar mereka membuka donasi dan mencari sponsor.

Guna menunjang dakwah, Komunitas Jaga Sesama memanfaatkan berbagai macam kanal media sosial, seperti akun Instagram (@jagasesama), akun Facebook (@JagaSesama), dan akun Youtube (@JagaSesamaSolo). Dalam setiap unggahan di media sosial, Komunitas Jaga Sesama menggunakan tagar khusus untuk menarik perhatian anak muda agar mengetahui lebih banyak mengenai komunitas ini, di antaranya: \#YoNgajiYoMasaKini, \#ThePowerOfHijrah, \#OraNgajiOraAji, \#IstiqomahUntilJannah, \#hijrahenggaksusah. Hal tersebut selaras dengan penjelasan Dimas Rahmat D, founder dan humas Komunitas Jaga Sesama: 
"Kita tentu menggunakan media sosial, seperti Youtube, Facebook, tapi paling aktif di Instagram. Untuk sharing informasi, video-video ceramah atau kegiatan, dan share jadwal ngaji. Kalau untuk strategi, kita dari hati ke hati, maksudnya hubungan antar jamaah. Misalnya kita bikin bakar-bakar di depan masjid untuk menjalin hubungan, atau selain di majelis kita kadang nongkrong bareng. Tapi untuk menarik attensi orang luar untuk ikut Jaga Sesama, kita hanya sebatas bikin postingan di Instagram, urusan dia mau datang ke kita atau tidak itu sudah bukan kuasa kita." (wawancara Dimas Rahmat D, founder dan humas Komunitas Jaga Sesama, 8 Maret 2019)

Pemaparan tersebut menemukan relevansinya manakala kita perhatikan akun Instagram Komunitas Jaga Sesama Solo. Mereka mampu menghadirkan konten-konten yang menarik dan menggambarkan selera anak muda. Misalnya, dapat dilihat pada unggahan pamflet Sunmori (Sunday morning ride) dengan visual seseorang mengendarai moge (motor gede) dan bersurban atau undangan ngaji rutin yang didesain serupa bungkus mie instan, iklan burger, bungkus penyedap rasa dan lainnya. Terlihat unik dan terkesan tidak formal. Desain lain yang sering diadaptasi oleh Komunitas Jaga Sesama adalah plesetan dari film yang sedang naik daun, seperti film Joker, Nanti Kita Cerita tentang Hari Ini, dan lainnya.

Pada perkembangannya, tidak mengherankan jika Komunitas Jaga Sesama cukup diminati anak-anak muda Solo dan menjadi ruang belajar agama dengan banyak anggota. Anggota Komunitas Jaga Sesama mempunyai beragam latar belakang dan motivasi. Pengakuan MI misalnya, anggota Komunitas Jaga Sesama ini menyampaikan bahwa pernah bermimpi meninggal bekali-kali dan dirinya sendiri yang melayat. Mimpi itu datang selama dua minggu tanpa henti. Sejak saat itu, kemudian tergerak mendalami agama dan mencari tempat untuk belajar iqro. Hingga akhirny,a seorang teman merekomendasikan Komunitas Jaga Sesama dan sampai sekarang ia belajar di sana. Pengakuan MI tersebut sedikit berbeda dengan kisah awal MF bergabung dengan Komunitas Jaga Sesama.

"Pada saat kuliah, karena saya anak seni, sayatatoan, gondrong, terjerumus dunia malam dan sebagainya. Namanya lingkungan pasti lama-lama kita bakal ikutan, pas kuliah sampai lulus itu parah sih, saya sering minum dan dugem. Bapakku seorang mubaligh jadi dia punya cara dakwah sendiri pada anak, tidak main kasar, keras, malah lembut, istilahnya kayak dilulu. Kamu tatoan le, ya tambahi lagi, mabuk le, ya besuk sing akeh. Setiap malam Bapak mesti bangunkan untuk salat tahajud, lama kelamaan aku sadar sendiri kok aku kurang ajar men dadi anak, nglunjak. Bersamaan dengan itu saya ikut Jaga Sesama dan disana juga banyak yang menuntun. Mulai detik itu Allah datangkan hidayah dan saya janji sudah tidak mau lagi mengulangi dosa yang sama." (wawancara MF, anggota Komunitas Jaga Sesama, 30 April 2020)

Kisah hijrah MF menunjukkan pentingnya posisi komunitas. Jika tidak berkomunitas dan tidak ada yang terus mengingatkan, besar kemungkinan MF kembali ke masa lalu yang kelam. MF merasa teman-teman di Komunitas Jaga Sesama membuatnya nyaman. Karena dakwah yang dilakukan tanpa paksaan dan penghakiman. Mula-mula MF diajak ngobrol santai, nongkrong, dan makan-makan, tidak langsung mengaji. Setelah nyaman, baru belajar agama dengan serius.

Kisah MF tersebut serupa dengan kisah LR yang mengaku pada awalnya ada perasaan takut dan malu dengan lingkungan baru (komunitas hijrah) yang sebelumnya 
tidak pernah dimasuki. Namun, karena di Komunitas Jaga Sesama dapat merangkul tanpa membedakan, LR pun merasa diterima, dan betah belajar agama di Komunitas Jaga Sesama, ada perasaan seperti belajar dengan teman sendiri, disokong pula tekad untuk terus membenahi diri.

Mengelola komunitas seperti Jaga Sesama memang menghadirkan tantangan tersendiri. Selain karena anggota atau jama'ahnya masih muda, sebagian dari jama'ah memiliki masa lalu yang buruk dan baru mulai belajar agama/mengaji, bahkan dari iqro. Sehingga perlu ada cara dakwah khusus untuk dapat merangkul anggota, menjadikan mereka konsisten belajar. Sunday morning ride, sahur on the road, dahar gratis, futsal, nasi Jumat, Bersami (belajar renang bersama Minggu pagi) dan Cuci Sepatu Bayar Seikhlasnya adalah cara-cara yang dilakukan Komunitas Jaga Sesama dalam upaya berdakwah ke kalangan muda.

\section{Manajemen Dakwah Komunitas Jaga Sesama Solo}

Kegiatan-kegiatan komunitas memerlukan manajemen agar terlaksana dengan baik dan tujuan komunitas dapat tercapai. Pada konteks Komunitas Jaga Sesama, manajemen yang dimaksud adalah manajemen dakwah. Ditilik dari perspektif manajemen dakwah, Komunitas Jaga Sesama Solo dapat dianalisis dengan paparan sebagai berikut:

Pertama, perencanaan dakwah (takhthith). Perencanaan pada Komunitas Jaga Sesama Solo dimulai dengan menentukan sasaran dakwah. Komunitas tersebut menentukan anak muda sebagai sasaran. Khususnya adalah anak muda yang ingin belajar Islam dari dasar, atau anak muda yang ingin berhijrah. Artinya mereka yang memiliki masa lalu kelam dan memiliki keinginan bertaubat serta memperbaiki diri. Komunitas Jaga Sesama menjadi wadah untuk mereka berkegiatan dan belajar agama.

Setelah mengetahui sasaran dakwah, maka langkah selanjutnya adalah menyusun rencana kegiatan yang akan dilaksanakan. Rencana kegiatan tentu disesuaikan dengan visi misi yang telah dirancang sebelumnya. Menyusun rencana kegiatan juga termasuk menyusun prioritas kegiatan. Pada Komunitas Jaga Sesama Solo, prioritas kegiatan adalah mengaji iqro dan Al Qur'an. Sebab dua hal tersebut dianggap sebagai hal mendasar khususnya bagi mereka yang baru berhijrah atau baru mempelajari Islam.

Perencanaan dakwah pada suatu komunitas juga meliputi perencanaan dan pemilihan ustaz yang menjadi pengampu kegiatan komunitas. Hal tersebut misalnya dapat terlihat pada sesi belajar fiqih di Komunitas Jaga Sesama Solo. Kajian fiqih diampu Habib Ali Bin Ali Assegaf, sosok yang dianggap memiliki ilmu mumpuni untuk membimbing anak-anak muda yang baru hijrah. Karakter dakwah Habib Ali Bin Ali Assegaf yang bisa diterima anak muda menjadi poin utama. Nama-nama lain yang dihadirkan untuk mengisi kajian di Komunitas Jaga Sesama juga berdasarkan kriteria yang sama, yakni memiliki kedalaman ilmu dan berjiwa muda (mampu berkomunikasi dengan anak muda perkotaan).

Selanjutnya, perencanaan dakwah juga menyangkut penentuan lokasi, waktu dan metode dakwah. Ketiga hal ini telah dibahas di bagian sebelumnya. Bahwa Komunitas Jaga Sesama Solo telah memiliki kegiatan rutin yang beragam serta lokasi tetap untuk melaksanakan kegiatan-kegiatan dakwah tersebut. Adapun mengenai metode dakwah, pada dasarnya Komunitas Jaga Sesama Solo melakukan dakwah konvensional seperti 
ceramah namun dikemas sedemikian rupa agar menarik minat generasi muda (dakwah dengan kemasan touring, traveling, futsal, dan lainnya). Penerimaan anggota bersifat terbuka, tanpa memandang latar belakang.

Kedua, pengorganisasian dakwah (tanzhim). Pengorganisasian dakwah pada sebuah komunitas identik dengan pembagian tugas. Sehingga membentuk struktur organisasi menjadi suatu kelaziman. Hal tersebut telah dilakukan oleh Komunitas Jaga Sesama Solo. Hanya saja, menurut pengakuan pengurus, struktur organisasi hanya formalitas belaka. Pada kenyataannya, banyak kegiatan komunitas yang dikerjakan bersama-sama, tanpa memandang jabatan seseorang di Komunitas Jaga Sesama. Tujuannya adalah untuk membangun persaudaraan dan menghilangkan "sekat" di Komunitas Jaga Sesama.

Kondisi seperti itu dapat dikatakan tidak taat manajemen, sebab seseorang bekerja tidak sesuai dengan tugas dan tanggung jawabnya. Namun, pada konteks komunitas, struktur yang longgar lebih diperlukan untuk menghindari kekakuan. Komunitas yang terlalu hirarkis dapat menghambat jalannya kegiatan-kegiatan komunitas. Cairnya sebuah komunitas membuatnya terhindar dari pemimpin yang otoriter. Menggunakan pola yang cenderung longgar dan cair membuat Komunitas Jaga Sesama Solo berhasil menjalakan kegiatan-kegiatan dakwah yang telah dicanangkan.

Ketiga, penggerakan dakwah (tawjih). Komunitas Jaga Sesama Solo memiliki ketua atau yang biasa disebut amir, yakni Widiyantoro S. Ketua atau amir ini bertanggung jawab terhadap jalannya komunitas. Selaku ketua/amir memiliki peran untuk mendinamisasi komunitas, memastikan semua bagian/divisi telah menjalankan peran untuk mencapai tujuan. Komunikasi intens antara pengelola dan anggota menjadi kunci keberhasilan penggerakan dakwah. Komunikasi yang baik, menunjang soliditas komunitas sehingga kegiatan-kegiatan yang dicanangkan dapat berjalan lancar.

Tantangan Komunitas Jaga Sesama Solo salah satunya adalah menjaga agar anggota dapat konsisten/istiqomah mengikuti kajian, mengaji (iqro, Al Qur'an) dan belajar Islam di komunitas. Sebagaimana diketahui, jamaah/anggota Komunitas Jaga Sesama Solo mayoritas bukanlah orang-orang yang datang untuk menambah pengetahuan agama, sebagian besar dari mereka bahkan baru tahu agama. Sehingga perlu langkah khusus untuk terus memotivasi mereka tetap berada di "jalur yang tepat". Tidak mengherankan sejumlah kegiatan ditempuh agar anak-anak muda yang berhijrah itu merasa betah berkomunitas di Jaga Sesama. Kegiatan Sunday Morning Ride, futsal, renang dan memanah merupakan upaya untuk menjadikan anggota merasa nyaman.

Pergerakan Komunitas Jaga Sesama Solo dapat pula disaksikan di media sosial, di instagram misalnya, dapat ditemukan tentang cara komunitas terus terhubung dengan anak muda, salah satunya dengan menghadirkan desain yang menarik dan kekinian. Terdapat upaya menghilangkan kesan bahwa dakwah adalah hal yang berat dan membosankan. Desain yang menarik dan khas anak muda sudah lazim digunakan oleh komunitas-komunitas hijrah lain.

Keempat, pengendalian dan evaluasi dakwah (riqabah). Komunitas Jaga Sesama Solo melakukan evaluasi atas kegiatan-kegiatan dakwah yang dilakukan. Salah satu evaluasi yang dilakukan menunjukkan bahwa beberapa kegiatan tidak berjalan maksimal dikarenakan tidak ada atensi dari para anggota untuk mengikuti kegiatan tersebut. Contohnya kegiatan Cuci Sepatu Bayar Seikhlasnya, Nasi Jum'at, mengaji al-Kahfi di Kamis malam, dan Sahur on the Road. 
Evaluasi yang dilakukan Komunitas Jaga Sesama berupa rapat bulanan yang menghadirkan pengurus inti. Pada rapat tersebut dibahas kendala-kendala yang mucul dalam menjalankan kegiatan, kemudian mencari solusi dari kendala yang terjadi. Kendala dalam mengelola komunitas salah satunya adalah menjaga konsistensi anggota dalam mengikuti kegiatan yang telah dicanangkan.

Mencermati manajemen dakwah yang dilakukan oleh Komunitas Jaga Sesama Solo dapat disaksikan bagaimana sebuah komunitas hijrah berupaya mencapai tujuan dakwah. Jalan yang dipilih adalah dengan mamanfaatkan youth culture, selaras dengan target dakwah yang dicanangkan. Kultur anak muda yang dekat dengan internet/media sosial dimanfaatkan Komunitas Jaga Sesama Solo melalui optimalisasi Instagram, Facebook, Twitter dan Youtube. Anak muda yang menyukai olahraga direspons dengan kegiatankegiatan seperti futsal, touring, memanah dan berkuda. Sesuatu hal yang dipelajari di komunitas pun merupakan hal "ringan" seperti kajian fiqih dan mengaji iqro/Al Quran.

Komunitas Jaga Sesama Solo dan komunitas hijrah pada umumnya menunjukkan perubahan strategi dakwah pada kelas menengah muslim. Jati, menyebut kelas menengah muslim Indonesia pasca orde baru terbagi menjadi dua yakni kelas intelegensia muslim dan kelas urban muslim. Kelas urban muslim melahirkan Islam populer yang berbasis gaya hidup, yang mengikuti perkembangan budaya masa kini mulai dari fashion, industri halal (makanan, hotel, pariwisata, bank) dan dakwah modern yang selaras zaman. Di sanalah dapat dilihat bahwa keberadan komunitas hijrah merupakan praktik Islam populer khas kelas menengah muslim (Jati, 2014).

\section{KESIMPULAN}

Pembahasan di atas bermuara pada kesimpulan bahwa Komunitas Jaga Sesama menjalankan manajemen dakwah untuk mewadahi generasi muda Solo belajar dasar Islam. Perencanaan dakwah (takhthith) ditempuh melalui menentukan sasaran dakwah, menyusun visi misi komunitas, serta menentukan ustaz pengampu kajian. Pengorganisasian dakwah (tanzhim) dilakukan dengan pembagian tugas kepada pengurus komunitas. Penggerakan dakwah (tawjih) dijalankan dengan menghadirkan kegiatan yang relevan dengan generasi muda dan optimalisasi media sosial. Adapun pengendalian dan evaluasi dakwah (riqabah) melalui evaluasi bulanan.

Penelitian ini berkontribusi pada kajian ilmu dakwah dengan memberikan gambaran mengenai praktik dakwah di kalangan kelas menengah muslim melalui komunitas hijrah. Bahwa pada suatu masa di sejumlah kota di Indonesia, dakwah anak muda menempuh cara-cara baru dengan meninggalkan dakwah gaya lama yang hanya terfokus pada ceramah di atas mimbar an sich. Komunitas hijrah dengan youth culture yang berkembang, dianggap oleh sebagian anak muda perkotaan sebagai sarana tepat untuk memperbaiki diri dan belajar dasar-dasar Islam yang selaras zaman. Dakwah dikemas semenarik mungkin, baik secara daring (di media sosial) maupun luring. Pada komunitas Jaga Sesama, dakwah dikemas dengan kegiatan touring (Sunday Morning Ride bersama Bikers Iqro Solo Raya), traveling (ziarah ke Gresik, Surabaya, Kudus), futsal, bermusik dan sebagainya. 


\section{DAFTAR PUSTAKA}

Buku:

Ikhwan, M. (2018). "Produksi Wacana Islam (is) Di Indonesia: Revitalisasi Islam Publik Dan Politik Muslim." In Literatur Keislaman Generasi Milenial; Transmisi, Apropriasi, Dan Kontestasi, edited by Noorhaidi Hasan. Yogyakarta: Pascasarjana UIN Sunan Kalijaga Press.

Munir, M., and Wahyu I. (2015). Manajemen Dakwah. Jakarta: Prenadamedia.

Wulandari, I. S. (2019). "Identitas Keagamaan: Pemuda Hijrah Di Kalangan Anak Muda." In Otoritas Keagamaan, Politik Dan Budaya Masyarakat Muslim. Yogyakarta: PPS UIN Sunan Kalijaga Yogyakarta.

\section{Jurnal dan Sumber Lain:}

Addini, A. (2019). "Fenomena Gerakan Hijrah Di Kalangan Pemuda Muslim Sebagai Mode Sosial." Journal of Islamic Civilization 1 (2) h. 109-118

Ahmadiy. (2016). "Islam Kâffah: Tinjauan Tafsir Q.S. Al-baqarah: 208." Syariati 2 (2) h. 187-196

Amna, A. (2019). “Hijrah Artis Sebegai Komodifikasi Agama.” Sosiologi Reflektif 13 (2) h. $331-50$

Annisa, F. (2018). "Hijrah Milenial: Antara Kesalehan Dan Populism.” Maarif 13 (1) h. 3854.

Dilawati, dkk. (2020). "Analisis Keberagamaan Pemuda Hijrah Komunitas Shift Perspektif Emik-Etik." Jurnal Perspektif 4 (1) h. 54-65

Fajriani, S. W., dan Yogi S. S. (2019). "Hijrah Islami Milenial Berdasarkan Paradigma Berorientasi Identitas." SOSIOGLOBAL: Jurnal Pemikiran Dan Penelitian Sosiologi 3 (2) h. 77-88

Farhan, A. (2020). “Narasi Hijrah: Sebuah Fenomena Living Qur'an Pada Komunitas Biker Muslim Bengkulu." El-Afkar: Jurnal Pemikiran Keislaman Dan Tafsir Hadis 9 (1) h. 166-183

Hadri, H. (2019). "Contemporary Religious Movement in Indonesia: A Study of Hijrah Festival in Jakarta in 2018." Journal of Indonesian Islam 13 (1) h. 230-65

Hayati, S. (2018). "Manajemen Dakwah Pada Sekolah Luar Biasa Islam (SLBI) Qothrunnada Banguntapan Bantul Daerah Istimewa Yogyakarta." Jurnal MD. 4 (2) h. 201-229

Hew, W. W. (2018). "The Art of Dakwah: Social Media, Visual Persuasion and the Islamist Propagation of Felix Siauw." Indonesia and the Malay World 46 (134) h. 61-79

Ilham, M. (2018). "Jaga Sesama, Wadah Belajar Agama." 2018. https://www.suaramerdeka.com/smcetak/baca/73867/jaga-sesama-wadahbelajar-agama.

Irmansyah, I. (2020). "Pemuda Hijrah: Antara Pietization Dengan Lifestyle Pada Komunitas Hijrah Yuk Ngaji Yogyakarta." Madania: Jurnal Ilmu-Ilmu Keislaman 10 (1) h. 46-56

Jati, W. R. (2014). "Tinjauan Perspektif Intelegensia Muslim Terhadap Genealogi Kelas Menengah Muslim Di Indonesia." Islamica: Jurnal Studi Keislaman. 9 (1) h. 1-29

___. (2015). "Islam Populer Sebagai Pencarian Identitas Muslim Kelas Menengah Indonesia." Teosofi: Jurnal Tasawuf Dan Pemikiran Islam. 5 (1) h. 139-163

Lyansari, K. N. (2018). "Hijrah Celebrity: Creating New Religiosities, Branding Economics of Lifestyle in the Age of Muslim Mass Consumption." Analisis: Jurnal Studi 
Keislaman 18 (2) h. 211-32

Prasanti, Ditha, dan Sri S. I. (2019). "Konstruksi Makna Hijrah Bagi Anggota Komunitas Let's Hijrah Dalam Media Sosial Line." Al Izzah: Jurnal Hasil-Hasil Penelitian. 14 (1) h. 106-19

Putri, S. H. (2019). "Manajemen Dakwah Malam Bina Iman Dan Takwa: Studi Pada Program Pemerintahan Kota Solok Sumatra Barat." Jurnal MD. 5 (2) h. 227-245

Reno. (2019). “14 Komunitas Berkolaborasi Gelar Solo Hijrah Day.” 2019. https://www.kiblat.net/2019/07/29/14-komunitas-berkolaborasi-gelar-solohijrah-day/.

Ritonga, A. R. (2016). “Memahami Islam Secara Kaffah: Integrasi Ilmu Keagamaan Dengan Ilmu-Ilmu Umum.” Islam Realitas: Journal of Islamic \& Social Studies 2 (2) h. 118-133

Sakhinah, S, dan Armawati A. (2019). "Persuasive Strategic Communication: Tabligh in Komunitas Anak Muda Berhijrah or Hijrah Youth Community." Dakwah 23 (1) h. 2239

Sari, A. N., dan Adi B. M. (2018). "Perilaku Komunikasi Pelaku Hijrah (Studi Fenomenologi Pelaku Hijrah Dalam Shift Gerakan Pemuda Hiijrah Di Kota Bandung).” Linimasa. 1 (1) h. 1-21.

Sari, T. Y., Fatimah H., dan Ratna N. (2020). "Hijrah and Islamic Movement in Social Media: A Social Movement Study of Anti-Dating Movement \#IndonesiaTanpaPacaran." Dinika: Academic Journal of Islamic Studies. 5 (1) h. 1-26

Sunesti, Y, Noorhaidi H., dan Muhammad N. A. (2018). "Young Salafi-Niqabi and Hijrah:Agency and Identity Negotiation." Indonesian Journal of Islam and Muslim Societies. 8 (2) h. 173-197

Surahman, S. (2018). "Publik Figur Sebagai Virtual Opinion Leader Dan Kepercayaan Informasi Masyarakat.” Wacana. 17 (1) h.1-18

Triantoro, Dony A., Eko S., dan Tri W. (2019). "Mengelola Hibridasi Identitas Anak Muda Islam: Studi Pada Lembaga Teras Dakwah Di Yogyakarta." Jurnal MD 5 (2) h. 113-39

Uberman, M. dan Shaul S. (2016). "Hijrah According to the Islamic State: An Analysis of Dabiq." Counter Terorist Trends and Analysis. 8 (9) h. 16-20

Ulfah, N. M. (2017). "Strategi Dan Manajemen Dakwah Lembaga Dakwah Islam Indonesia (LDII) Kecamatan Tugu Kota Semarang." Jurnal Ilmu Dakwah 35 (2) h. 207-224

Zulhazmi, A. Z., dan Dewi A. S. H. (2018). "Da'wa, Muslim Millennials and Social Media." Lentera: Jurnal Imu Dakwah Dan Komunikasi. 2 (2) h. 121-38 